University of Nebraska - Lincoln

DigitalCommons@University of Nebraska - Lincoln

Faculty Publications from the Harold W. Manter Laboratory of Parasitology

$2-1983$

\title{
Centrorhynchus kuntzi from the USA with Description of the Male and Redescription of $C$. spinosus (Acanthocephala: Centrorhynchidae)
}

\author{
Brent B. Nickol \\ University of Nebraska - Lincoln, bnickol1@unl.edu
}

Follow this and additional works at: https://digitalcommons.unl.edu/parasitologyfacpubs

Part of the Parasitology Commons

Nickol, Brent B., "Centrorhynchus kuntzi from the USA with Description of the Male and Redescription of C. spinosus (Acanthocephala: Centrorhynchidae)" (1983). Faculty Publications from the Harold W. Manter Laboratory of Parasitology. 355.

https://digitalcommons.unl.edu/parasitologyfacpubs/355

This Article is brought to you for free and open access by the Parasitology, Harold W. Manter Laboratory of at DigitalCommons@University of Nebraska - Lincoln. It has been accepted for inclusion in Faculty Publications from the Harold W. Manter Laboratory of Parasitology by an authorized administrator of DigitalCommons@University of Nebraska - Lincoln. 


\title{
CENTRORHYNCHUS KUNTZI FROM THE USA WITH DESCRIPTION OF THE MALE AND REDESCRIPTION OF C. SPINOSUS (ACANTHOCEPHALA: CENTRORHYNCHIDAE)
}

\author{
Brent B. Nickol \\ School of Life Sciences, University of Nebraska-Lincoln, Lincoln, Nebraska 68588-0118
}

ABSTRACT: Centrorhynchus kuntzi Schmidt and Neiland, 1966, reported here for the first time from the USA, occurred in Bubo virginianus in Florida and Buteo jamaicensis, Buteo lineatus, and Buteo platypterus in Louisiana. Centrorhynchus kuntzi males, previously undescribed, were 10 to $29 \mathrm{~mm}$ long with a large swelling near the anterior end of the trunk. The proboscis, averaging $1.14 \mathrm{~mm}$ in length and with a marked swelling near the middle at the level of proboscis receptacle insertion, was armed with 26 to 31 (usually 29) longitudinal rows of 22 to 26 (usually 24) hooks each. The first seven to nine (usually 8 ) hooks in each row possessed long, simple roots and the following 14 to 18 (usually 16) were rootless spines. Centrorhynchus spinosus (Kaiser, 1893) Van Cleave, 1924, occurred in Melanerpes carolinus in Louisiana and Strix varia in Florida and Louisiana. Centrorhynchus spinosus resembles $C$. kuntzi in the range in number of longitudinal rows of proboscis hooks, although $C$. kuntzi usually possesses one less row (30 in $\$, 29$ in $\delta)$, in the total number of proboscis hooks and spines in each longitudinal row, and in possessing a laterally flattened papilla at the posterior end of females. Centrorhynchus spinosus differs from $C$. kuntzi in lacking proboscis and trunk inflations, possessing a shorter proboscis, and having more, large, rooted proboscis hooks (usually 9 in $\$, 10$ in $\delta$ ) and fewer rootless spines (usually 15) in each longitudinal row.

Centrorhynchus spinosus (Kaiser, 1893) Van Cleave, 1924, is purported to be a "well known" species of Acanthocephala and has been reported in the USA from seven avian species. Descriptions are based on the original (Kaiser, 1893) of an unspecified number of specimens, one immature female specimen (Van Cleave, 1916), and 22 specimens from a "Galapagos hawk" (Van Cleave, 1940). Van Cleave (1924) studied additional specimens identified by him as $C$. spinosus from the Leidy collection, but only slightly modified his 1916 description. Although they have not been located for reexamination, it is believed that the Galapagos specimens were not of this species and probably were representatives of C. kuntzi Schmidt and Neiland, 1966. When Van Cleave (1940) extended the definition of $C$. spinosus to include the Galapagos specimens, thereby incorporating features later ascribed to C. kuntzi, he provided a description that may have prevented recognition of $C$. kuntzi in the USA.

Centrorhynchus kuntzi males were not available for the original species description (Schmidt and Neiland, 1966) and have not been subsequently described. Further, the existing description of $C$. spinosus, based on few specimens and incorporating some features of a second species, prevented Schmidt and Neiland (1966) from ad-

Received 19 January 1982; accepted 17 May 1982. equately distinguishing C. kuntzi from C. spinosus.

A large collection of Centrorhynchus from Louisiana has made sufficient material available to permit a fuller description of $C$. spinosus, description of $C$. kuntzi males (Fig. 1), and better distinction between the two species.

\section{MATERIALS AND METHODS}

The following descriptions are based on $54(349,20 \delta)$ specimens of $C$. spinosus and $161\left(969,65 \delta^{\circ}\right)$ specimens of $C$. kuntzi from birds collected in Louisiana. Table I lists sources and prevalence of these specimens. Additionally, the specimen (U.S.B.A.I. Helminthol. Coll., Hassall Coll. No. 6307) designated by Van Cleave (1916) as "type" of $C$. spinosus; the holotype (USNM Helminthol. Coll. No. 60771) and paratypes (USNM Helminthol. Coll. No. 60772) of C. kuntzi; and $10 \mathrm{spec}-$ imens of Centrorhynchus from Bubo virginianus and one from Strix varia, all from Florida, were studied.

Ranges in the redescription of $C$. kuntzi incorporate Schmidt and Neiland's (1966) original data (the types did not deviate), but means are for specimens of the present study only. The redescription of $C$. spinosus is based solely on present specimens with appropriate comparisons to type material and previously published descriptions in the Discussion.

All measurements are in micrometers with means in parentheses unless otherwise noted.

\section{RESULTS}

\section{Redescriptions \\ Centrorhynchus spinosus (Kaiser, 1893) Van Cleave, 1924}

General: Trunk cylindrical, elongate, with slight constriction anteriorly, but swelling lacking. Neck short, 22 to 53 (40) long and 312 to 413 (356) wide at base. 
Proboscis nearly cylindrical, slight constriction at insertion of receptacle but marked swelling lacking; armed with 29 to 33 longitudinal rows of 22 to 27 hooks each. First eight to 11 (usually 9 in $\$, 10$ in 8 ) hooks in each row with long, simple roots; next 13 to 17 (usually 15) rootless spines. Anteriormost spine in each row transitional, with four short, laterally directed, rootlike processes. Hooks 31 to 43 (36) long anteriad, 34 to 48 (40) long at end of rooted row; rootless spines 29 to 46 (37) long. Largest hook-roots 53 to 70 (59) long. Doublewalled proboscis receptable inserted at slight constriction in proboscis, 1.06 to $1.78 \mathrm{~mm}$ (1.25) long. Brain, about in middle of receptacle just posterior to necktrunk junction, elliptical, 140 to 254 (192) long by 58 to $67(60)$ wide. Lemnisci, 1.10 to $1.78 \mathrm{~mm}$ (1.57) long, extend well posteriad of the proboscis receptacle.

Male: Mature males 20.0 to $27.2 \mathrm{~mm}$ (23.6) long by 0.8 to $1.1 \mathrm{~mm}(0.9)$ at widest point (just anterior to slight constriction in trunk), 0.3 to $0.5 \mathrm{~mm}(0.4)$ wide at neck-trunk junction, 0.4 to $0.7 \mathrm{~mm}(0.5)$ wide at posterior end. Proboscis 806 to 1,018 (965) long by 173 to 230 (197) wide at apex, 240 to 264 (250) at widest point (just anterior to insertion of receptacle), 202 to 235 (218) wide at receptacle insertion, 307 to 356 (332) wide at base; armed with 29 to 32 (usually 30 ) longitudinal rows of 23 to 27 (usually 25) hooks each. Testes two, located behind slight constriction in trunk, elliptical, approximately equal in size, 595 to 922 (748) long by 278 to 614 (380) wide. Four tubular cement glands of slightly different lengths begin at rear of second testis and extend 6.9 to $11.4 \mathrm{~mm}(9.1)$ posteriad. Saefftigen's pouch 1.4 to $1.8 \mathrm{~mm}$ (1.5) long. Entire male system occupying 66.1 to $72.9 \%(69.3)$ of trunk length.

Female: Gravid females, containing eggs with fully developed membranes and spined acanthors, 19.0 to $33.7 \mathrm{~mm}(25.4)$ long by 0.4 to $1.2 \mathrm{~mm}(0.8)$ at widest point (just anterior to slight trunk constriction), 0.4 to $0.8 \mathrm{~mm}(0.4)$ wide at neck-trunk junction, 0.6 to 1.0 $\mathrm{mm}(0.7)$ wide at posterior end. Trunk with prominent, laterally flattened papilla at posterior end, varying in shape from digitiform to conical depending upon degree of trunk distension by eggs. Proboscis 931 to 1,104 $(1,014)$ long by 173 to 259 (194) wide at apex, 240 to 356 (282) wide at widest point (just anterior to insertion of receptacle), 221 to 336 (285) wide at receptacle insertion, 317 to 432 (361) wide at base; armed with 30 to 33 (usually 31 ) longitudinal rows of 22 to 26 (usually 24) hooks each. Reproductive tract, anterior edge of uterine bell to subterminal genital pore, 1.7 to $2.4 \mathrm{~mm}$ (2.0) long; occupying 6.8 to $9.6 \%$ (8.1) of trunk length.

Eggs: Dissected from body cavity or measured through body wall, eggs 42 to 53 (47) long by 17 to 22 (19) wide; living eggs passed by females in water 50 to 55 (53) long by 22 wide. Thin outer shell sculptured with longitudinal ridges and grooves. Fertilization membrane with small polar prolongations.

\section{Centrorhynchus kuntzi Schmidt and Neiland, 1966}

General: Trunk cylindrical, elongate with large swelling near anterior end. Trunk width at swelling approximately three times greater than at junction with neck. Neck short, 21 to 72 (43) long and 288 to 590 (416) wide at base. Proboscis nearly cylindrical except for marked swelling near middle at level of proboscis receptacle insertion; armed with 26 to 35 longitudinal rows of 22 to 27 hooks each. First seven to nine (usually 8 ) hooks in each row with long, simple roots; next 14 to 18 (usually 16) rootless spines. Anteriormost spine in each row transitional, with four short, laterally directed, rootlike processes. Hooks 41 to 50 (46) long anteriad, 36 to 48 (39) long at end of rooted row; rootless spines 29 to 48 (36) long. Largest hook-roots 53 to 75 (64) long. Double-walled proboscis receptacle inserted at base of proboscis swelling, 1.08 to $1.87 \mathrm{~mm}$ (1.35) long. Brain, about in middle of receptacle just posterior to neck-trunk junction, elliptical, 154 to 216 (190) long by 43 to 62 (57) wide. Lemnisci, 1.10 to $2.74 \mathrm{~mm}$ (2.02) long, extend well posteriad of the proboscis receptacle.

Male: Mature males 10.0 to $29.0 \mathrm{~mm}$ (19.1) long by 0.7 to $1.8 \mathrm{~mm}$ (1.3) wide at swelling, 0.4 to $0.6 \mathrm{~mm}$ (0.4) wide at neck-trunk junction, 0.4 to $0.8 \mathrm{~mm}(0.6)$ wide at posterior end. Proboscis 816 to $1,296(1,140)$ long by 168 to $278(220)$ wide at apex, 288 to $348(316)$ wide at swelling, 240 to 289 (257) wide at receptacle insertion at base of swelling, 307 to 528 (385) wide at base; armed with 26 to 31 (usually 29) longitudinal rows of 22 to 26 (usually 24 ) hooks each. Testes two, at least one located in trunk swelling, elliptical, approximately equal in size, 499 to 1,104 (792) long by 108 to 461 (259) wide. Four tubular cement glands of slightly different lengths begin at rear of second testis and extend 9.5 to $15.4 \mathrm{~mm}$ (12.2) posteriad. Saefftigen's pouch 1.2 to $2.0 \mathrm{~mm}$ (1.6) long. Entire male system occupying 72.9 to $84.0 \%$ (77.7) of trunk length.

Female: Gravid females, containing eggs with fully developed membranes and spined acanthors, 20.0 to $48.0 \mathrm{~mm}$ (37.4) long by 1.0 to $2.0 \mathrm{~mm}$ (1.5) wide at swelling, 0.5 to $0.6 \mathrm{~mm}(0.5)$ wide at neck-trunk junction, 0.8 to $1.4 \mathrm{~mm}(1.0)$ wide at posterior end. Trunk with prominent, laterally flattened papilla at posterior end, varying in shape from digitiform to conical depending upon degree of trunk distension by eggs. Proboscis 870 to $1,709(1,257)$ long by 186 to $288(249)$ wide at apex, 288 to 413 (345) wide at swelling, 240 to $326(265)$ wide at receptacle insertion at base of swelling, 360 to 590 (405) wide at base; armed with 27 to 35 (usually 30 ) longitudinal rows of 23 to 27 (usually 24) hooks each. Reproductive tract, anterior edge of uterine bell to subterminal genital pore, 1.2 to $2.1 \mathrm{~mm}$ (1.7) long; occupying 3.8 to $6.5 \%$ (5.0) of trunk length.

Eggs: Dissected from body cavity or measured through body wall, eggs 41 to 60 (51) long by 15 to 22 (20) wide; thin outer shell sculptured with longitudinal ridges and grooves. Fertilization membrane with small polar prolongations.

Specimens deposited: Centrorhynchus kuntzi, USNM Helminthol. Coll. Nos. 76604 (o) and 76605 (\$); $C$. spinosus, USNM Helminthol. Coll. Nos. 76606 (\&) and 76607 ( $\left.{ }^{\circ}\right)$.

Hosts and localities: See Table I.

Site of infection: All specimens of this study were from the small intestine.

\section{Remarks}

Centrorhynchus spinosus and C. kuntzi resemble each other in the number of longitudinal rows of proboscis hooks. They also have the same 
TABLE I. Host and geographical distribution of confirmed Centrorhynchus spinosus and C. kuntzi.

\begin{tabular}{|c|c|c|c|c|c|c|}
\hline & $\begin{array}{l}\text { No. } \\
\text { exam. }\end{array}$ & $\begin{array}{l}\text { No. } \\
\text { inf. }\end{array}$ & Range & $\begin{array}{l}\bar{x} / \text { inf. } \\
\text { bird }\end{array}$ & Locality & Reference \\
\hline \multicolumn{7}{|l|}{ Centrorhynchus spinosus } \\
\hline Accipiter cooperii & & & & & Connecticut: North Franklin & $\begin{array}{l}\text { USNM Helminthol. Coll. } \\
\text { No. } 40620\end{array}$ \\
\hline Bubo virginianus & & & & & Florida: Alachua Co. & This study \\
\hline Herodias egretta & & 1 & 1 & 1.0 & Unknown & Van Cleave, 1916 \\
\hline $\begin{array}{l}\text { Melanerpes carolinus } \\
\text { Strix varia }\end{array}$ & 53 & 3 & $1-2$ & 1.7 & $\begin{array}{l}\text { Louisiana: Tangipahoa Par. } \\
\text { Florida: Pasco Co. }\end{array}$ & $\begin{array}{l}\text { This study } \\
\text { This study }\end{array}$ \\
\hline $\begin{array}{l}\text { S. varia } \\
\text { Unknown }\end{array}$ & 8 & 6 & $2-10$ & 8.2 & $\begin{array}{l}\text { Louisiana: East Baton Rouge, Tangipahoa, } \\
\text { and West Baton Rouge par. } \\
\text { Florida }\end{array}$ & $\begin{array}{l}\text { This study } \\
\text { Kaiser, } 1893\end{array}$ \\
\hline \multicolumn{7}{|l|}{ Centrorhynchus kuntzi } \\
\hline B. virginianus & & & & & Florida: Alachua Co. & This study \\
\hline Buteo jamaicensis & 3 & 1 & 2 & 2.0 & Louisiana: Iberville Par. & This study \\
\hline Buteo lineatus & 3 & 3 & $11-72$ & 36.3 & Louisiana: Pointe Coupee Par. & This study \\
\hline Buteo magnirostris & & 1 & 3 & 3.0 & Nicaragua: Rio Escondido, El Recreo & Schmidt and Neiland, 1966 \\
\hline Buteo platypterus & 2 & 2 & $23-27$ & 25.0 & Louisiana: Iberville Par. & This study \\
\hline
\end{tabular}

number of hooks in each row (22-27), but in $C$. spinosus there are more (8-11) large, rooted ones and fewer (13-17) rootless spines than in $C$. kuntzi (7-9 and 14-18, respectively). The usual numbers of large rooted hooks ( 9 in $\$, 10$ in of, C. spinosus; 8 in both sexes, $C$. kuntzi) and rootless spines ( 15 and 16 in both sexes of $C$. spinosus and $C$. kuntzi, respectively) show the same distinction as do the ranges. Schmidt and Neiland (1966) noted that hooks of $C$. spinosus are longer than those of C. kuntzi, but this was based on reports of Kaiser (1893) and Van Cleave (1924) of several specimens described as having unusually long hooks. No such specimen was observed in the present collection and hook lengths of the two species were similar.

Schmidt and Neiland (1966) reported that $C$. spinosus possesses a longer proboscis than does $C$. kuntzi. The proboscis length they cited for $C$. spinosus was given by Van Cleave (1924) for specimens from a Galapagos hawk and greatly exceeds that of all previous reports. The Galapagos hawk specimens, because of other features, are thought to be $C$. kuntzi (see Discussion). The original description of $C$. kuntzi reported a shorter proboscis, but only one (holotype) of the three specimens upon which it was based had a fully evaginated proboscis. Reexamination of that specimen confirmed the reported length; however, proboscides of female $C$. kuntzi of the present collection were seldom less than 1,000 long and averaged 1,257 long. Those of males averaged 1,140 long. Proboscides of $C$. spinosus females, on the other hand, were frequently less than 1,000 long and averaged only 1,014 long.
Proboscides of males averaged only 963 long. Now that male $C$. kuntzi and larger collections of both $C$. kuntzi and $C$. spinosus have been studied, it is evident that the proboscis of $C$. $k u n t z i$ is longer than that of $C$. spinosus.

Proboscides of $C$. spinosus and $C$. kuntzi differ also in shape and width (Figs. 2, 3). Those of $C$. $k u n t z i$ are wider and possess pronounced swellings whereas the narrower proboscides of $C$. spinosus are slightly constricted at the receptacle insertion but lack marked swellings.

The most conspicuous difference between $C$. spinosus and $C$. kuntzi is in trunk shape (Figs. $4,5)$. Although trunk lengths are similar, C. spinosus is much more slender and lacks the conspicuous inflation of C. kuntzi. All known Centrorhynchus cystacanths possess inflated foretrunks, but in birds $C$. spinosus juveniles assume a nearly cylindrical shape at least by the time they are $7.5 \mathrm{~mm}$ long, well short of the length at maturity. Figures 6 and 7 compare trunk shapes of equal-sized juvenile $C$. spinosus and C. kuntzi.

Females of both $C$. spinosus and $C$. kuntzi possess laterally flattened papillae at the posterior end. Schmidt and Neiland (1966) believed C. kuntzi to differ from C. spinosus in possession of this process. Although not adequately illustrated by Van Cleave (1916, Fig. 1), examination of the specimen (U.S.B.A.I. Helminthol. Coll., Hassall Coll. No. 6307) designated a "type" by Van Cleave, for what he believed to be the first description of $C$. spinosus, revealed the terminal papilla. Van Cleave (1924) later described "... lateral postgenital papillae" for $C$. spinosus. The 

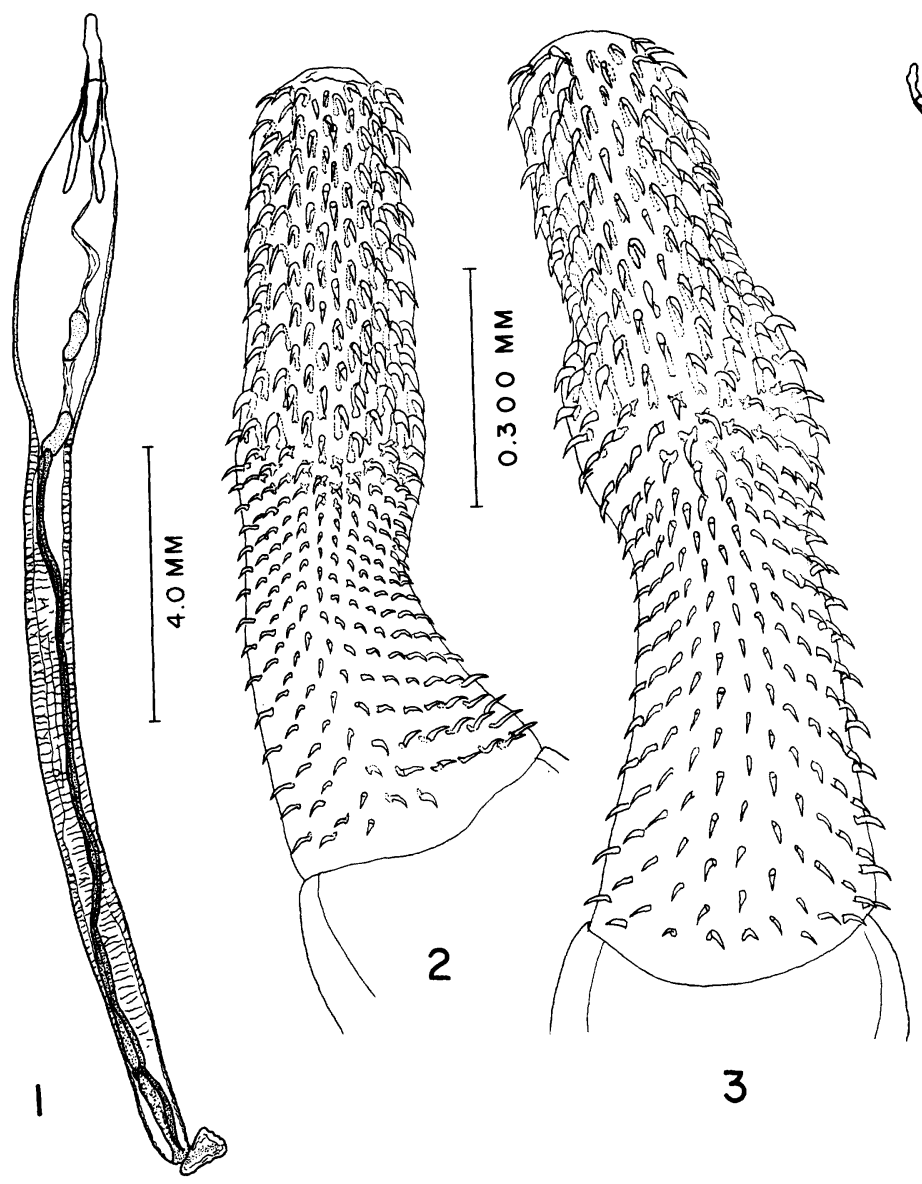

3

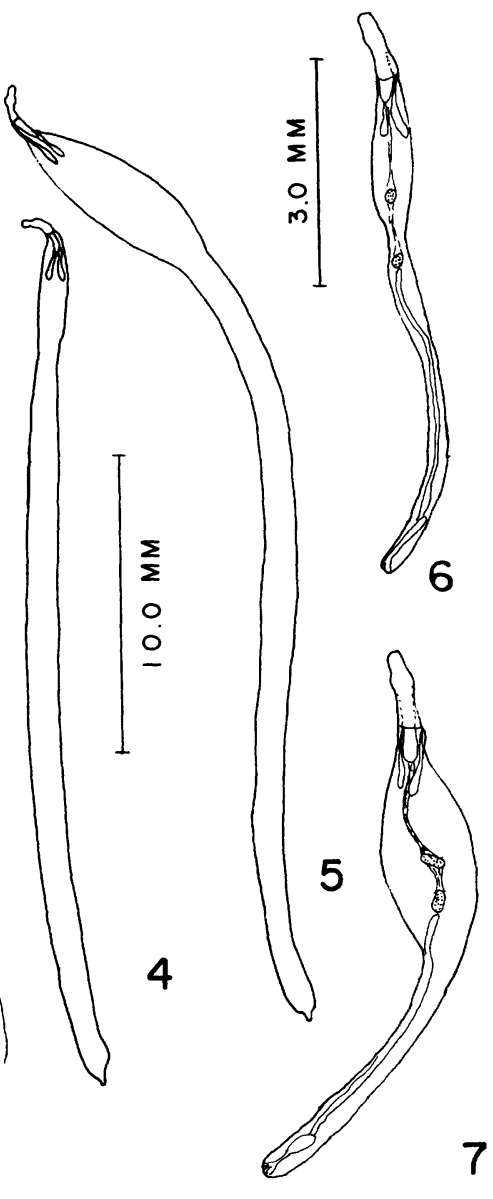

FIGUREs 1-7. Camera lucida drawings of Centrorhynchus spinosus and C. kuntzi. 1. C. kuntzi, adult male. 2. C. spinosus, proboscis. 3. C. kuntzi, proboscis. 4. C. spinosus, outline of female trunk-shape. 5. C. kuntzi, outline of female trunk-shape. 6. C. spinosus, 7.5-mm-long juvenile male from Strix varia. 7. C. kuntzi, 7.5mm-long juvenile male from Buteo jamaicensis. The projection beside Figure 6 applies equally to Figures 6 and 7.

papillae vary considerably in shape, from digitiform in young females to conical in older, distended worms, but no consistent difference between the two species was detected.

\section{DISCUSSION}

Van Cleave (1916) reported what he believed to be an undescribed species of Acanthocephala from Herodias egretta taken from an unmentioned locality. Based on a single, immature female he described and named Centrorhynchus spinosus. His description matches that given here in all regards except proboscis length and trunk width. Examination of his type specimen (U.S.B.A.I. Helminthol. Coll., Hassall Coll. No.
6307) revealed that the proboscis was partially invaginated and that Van Cleave's (1916) reported length of 650 was of the evaginated portion only. The diameter of the anterior part of the body was reported to be $6.6 \mathrm{~mm}$ (Van Cleave, 1916) and represents a misplaced decimal point as the type specimen actually measures 0.659 $\mathrm{mm}$. With these corrections, Van Cleave's first description of $C$. spinosus agrees fully with the redescription given here.

Kaiser (1893) described Echinorhynchus spinosus from an unknown host collected in Florida. Except that he considered the posterior portion of the proboscis to be a spined neck, his description differs from the present redescription in only 
two respects. Some of his specimens were longer (up to $45 \mathrm{~mm}$ \%; $60 \mathrm{~mm}$ ) and although most hook lengths were within the range reported here, some were described as 62 long. Van Cleave (1924) also noted that some hooks of this species were very long (ca. 60), but stated that most were about 48 long. Kaiser's specimens are unavailable for study.

Van Cleave (1924) examined specimens from Strix nebulosa, great gray owl, collected in Florida and identified as Echinorhynchus hystrix and E. caudatus by Leidy. He concluded that Leidy's specimens and his from $H$. egretta were conspecific with $E$. spinosus of Kaiser, making the correct generic assignment and name Centrorhynchus spinosus (Kaiser, 1893) Van Cleave, 1924. His accompanying description of Leidy's specimens added egg dimensions (48-54 long and 24 wide) and the fact that female trunks terminate in papillae to the description of the species. Both of these features are in agreement with the present redescription.

In a report on Acanthocephala collected by the Allan Hancock Pacific Expedition, Van Cleave (1940) identified specimens from an unknown "Galapagos hawk," collected from the Galapagos Islands, as $C$. spinosus. In the accompanying description he noted that mature worms had conspicuous inflations of the trunks; proboscides longer than originally described, 1.0 to $1.3 \mathrm{~mm}$ long; and eggs 50 to 60 by 20 to 24. Previously, no report of $C$. spinosus had mentioned or illustrated other than a fully cylindrical trunk. Proboscis and egg lengths exceeded all previous reports for $C$. spinosus. In each of these three features, the Galapagos specimens differed from previous descriptions of $C$. spinosus and matched subsequent descriptions (Schmidt and Neiland, 1966; present study) of C. kuntzi. The fact that Van Cleave did not recognize the Galapagos specimens as distinct from C. spinosus (probably resulting from the fact that then-existing descriptions had been based on very few specimens) may have permitted the occurrence of $C$. kuntzi in the USA to go unnoticed until now.

It is unlikely that all previous reports of $C$. spinosus can be verified or corrected. However, all specimens in the USNM Helminthol. Coll. identified as this species have been reexamined. Specimens from Bubo virginianus, great horned owl, and Strix varia, barred owl (Nos. 40328 and 40329, respectively), collected in 1933 at Ithaca,
New York, proved to be $C$. conspectus Van Cleave and Pratt, 1940. Specimens from S. nebulosa, great gray owl, from North Carolina in 1936 (No. 41752) were also $C$. conspectus. Only the specimen deposited by Van Cleave (1916) as his holotype and a specimen from Accipiter cooperii, Cooper's hawk, collected in 1939 at North Franklin, Connecticut, proved to be $C$. spinosus. Nickol (1969) reported C. spinosus from $S$. varia, Melanerpes carolinus (= Centurus carolinus), red-bellied woodpecker, Buteo platypterus, broadwinged hawk, and $B$. lineatus, red-shouldered hawk, all collected in southern Louisiana. Only the specimens from $S$. varia and $M$. carolinus are $C$. spinosus; those from the other hosts are C. kuntzi (Table I).

Ten of several dozen acanthocephalans from $B$. virginianus collected in Florida were stained and mounted for critical examination. Two of the 10 were $C$. kuntzi and eight were $C$. spinosus. In this collection of mixed species, there was no intermediate form. It appears that although these species are morphologically variable, distinctions outlined here do not grade into each other.

\section{ACKNOWLEDGMENTS}

Drs. Wilbur L. Bullock, University of New Hampshire, and Gerald D. Schmidt, University of Northern Colorado, graciously loaned the Florida specimens from Strix varia and Bubo virginianus, respectively. Mr. Willard W. Becklund and Dr. J. Ralph Lichtenfels made available specimens from the USNM Helminthological Collection.

\section{LITERATURE CITED}

KAISER, J. E. 1893. Die Acanthocephalen und ihre Entwickelung. I. Theil. Biblioth. Zool. 7: 1-136.

NiCKOL, B. B. 1969. Acanthocephala of Louisiana Picidae with description of a new species of $\mathrm{Me}$ diorhynchus. J. Parasitol. 55: 324-328.

Schmidt, G. D., AND K. A. NeILAND. 1966. Helminth fauna of Nicaragua. III. Some Acanthocephala of birds, including three new species of Centrorhynchus. J. Parasitol. 52: 739-745.

Van Cleave, H. J. 1916. Acanthocephala of the genera Centrorhynchus and Mediorhynchus (new genus) from North American birds. Trans. Am. Microsc. Soc. 35: 221-232.

-1924. A critical study of the Acanthocephala described and identified by Joseph Leidy. Proc. Acad. Nat. Sci. Philadelphia 76: 279-334.

. 1940. The Acanthocephala collected by the Allan Hancock Pacific Expedition, 1934. Rep. Hancock Pacific Expeditions 2: 501-527. 